\title{
Production and Survival of Projection Neurons in a Forebrain Vocal Center of Adult Male Canaries
}

\author{
John R. Kirn, Arturo Alvarez-Buylla, and Fernando Nottebohm \\ The Rockefeller University Field Research Center, Millbrook, New York 12545
}

\begin{abstract}
Neurons are produced in the adult canary telencephalon. Many of these cells are incorporated into the high vocal center (nucleus HVC), which participates in the control of learned song. In the present work, ${ }^{3} \mathrm{H}$-thymidine and fluorogold were employed to follow the differentiation and survival of HVC neurons born in adulthood. We found that many HVC neurons born in September grow long axons to the robust nucleus of the archistriatum (nucleus RA) and thus become part of the efferent pathway for song control. Many of these new neurons have already established their connections with RA by $30 \mathrm{~d}$ after their birth. By $240 \mathrm{~d}, 75-80 \%$ of the September-born HVC neurons project to RA. Most of these new projection neurons survive at least 8 months. The longevity of HVC neurons born in September suggests that these cells remain part of the vocal control circuit long enough to participate in the yearly renewal of the song repertoire.
\end{abstract}

Male canaries (Serinus canaria) learn their song as juveniles by reference to auditory information (Marler and Waser, 1977). In subscquent years, they modify their repertoire after the end of the breeding season, when many new song syllables are added. Initially these syllables are produced in an unstable manner, but they become fully stereotyped by the following spring (Nottebohm and Nottebohm, 1978; Nottebohm et al., 1987). The high vocal center of the neostriatum (HVC; incorrectly named hyperstriatum ventralis, pars caudalis when first described; (Nottebohm et al., 1976) plays an important role in the production of learned song (Nottebohm et al., 1976; McCasland and Konishi, 1981; Simpson and Vicario, 1990). HVC is also remarkable because it continues to add new neurons in adulthood (Goldman and Nottebohm, 1983; Paton and Nottebohm, 1984; Burd and Nottebohm, 1985); the new neurons replace older ones, which presumably die (Nottebohm, 1985; Alvarez-Buylla et al., 1990a). HVC neurons produced in adulthood may be involved in the acquisition and retention of learned song (Nottebohm, 1989). There are no precedents for neuronal replacement in the adult telencephalon, and thus understanding the behavioral significance of this phenomenon is of considerable interest. If the new neurons store information related to the new song syllables adult canaries acquire every year, then the lifespan of the new neurons should be at least as long as that of the new syllables.

\footnotetext{
Received Aug. 13, 1990; revised Jan. 18, 1991; accepted Feb. 1, 1991.

This work was supported by NIH Grant MH18343 to F.N., by NIH Research Fellowship 2F32 NS08340 to J.R.K., and by Biomedical Research Support Grant S07RR07065 awarded to Rockefeller University by the Division of Research Resources, NIH.

Correspondence should be addressed to John Kirn, The Rockefeller University Field Research Center, RR2 Box 38B, Millbrook, NY 12545.

Copyright (C) 1991 Society for Neuroscience $0270-6474 / 91 / 111756-07 \$ 03.00 / 0$
}

The HVC of songbirds is anatomically discrete, and its connections have been described (Nottebohm et al., 1976, 1982). Many HVC neurons project to the robust nucleus of the archistriatum (RA; Fig. 1 $A, B$ ). RA also is part of the efferent pathway for the control of learned song (Nottebohm et al., 1976, 1982; Bottjer et al., 1989). The present article describes the recruitment and survivorship of new neurons, including RAprojecting neurons, in the HVC of adult canaries. We show that new neurons born in the month of September survive for at least 8 months and argue that therefore they could be involved with the yearly renewal of a male canary's song repertoire.

\section{Materials and Methods}

Thirty-six adult males (17 months old) from our close-bred colony of Belgian Waterslager canaries were given intramuscular (Musculus pectoralis) injections of ${ }^{3} \mathrm{H}$-thymidine $(6.7 \mathrm{Ci} / \mathrm{mmole}$; New England $\mathrm{Nu}$ clear; $2.5 \mu \mathrm{Ci} / \mathrm{gm}$ body weight) every $12 \mathrm{hr}$ for $4 \mathrm{~d}$ during mid-September to label neurons born in adulthood. The month of September was chosen because previous work indicated that early fall represents a particularly active period for vocal learning in the adult canary (Nottebohm et al., 1987) and also a time of high rates of new HVC neuron incorporation (Alvarez-Buylla et al., 1990a; F. Nottebohm, unpublished observations). Birds were killed $1,2,3,4,5$ or 8 months $(31-33 \mathrm{~d}, 61-65 \mathrm{~d}, 88-93 \mathrm{~d}$, 119-123 d, 152-155 d, and 240-246 d respectively) after the last ${ }^{3} \mathrm{H}-$ thymidine injection. Three days prior to death, the fluorescent retrograde tracer fluorogold (Schmued and Fallon, 1986) was injected stereotaxically into RA in both hemispheres using coordinates derived from an atlas of the canary brain (Stokes et al., 1974), thereby labeling RA-projecting HVC neurons with fluorescence.

Three animals received fluorogold into one RA and fluorescent latex microspheres (Luma Fluor, Inc.) into the other RA $30 \mathrm{~d}$ after ${ }^{3} \mathrm{H}$-thymidine treatment. The purpose of using different retrograde tracers was to gain independent confirmation of the birth of projection neurons in adulthood and to compare the number of neurons backfilled with fluorescent microspheres (beads) and fluorogold. Beads are well known for their capacity to remain trapped intracellularly (Katz et al., 1984) and thus could not pass from projection neurons to neighboring interneurons, a process that might confound the scoring of adult-formed neuron phenotype.

Surgery. Prior to surgery, birds were deeply anesthetized with intramuscular injections of Chloropent (Fort Dodge Labs, Fort Dodge, IA) supplemented with Metofane (Pitman-Moore, Washington Crossing, NJ). Each bird was placed in a stereotaxic instrument; a midline scalp incision was made, and the skin was retracted, exposing the dorsal skull surface. Small holes were made in the skull, exposing the brain caudal to $\mathrm{HVC}$, and a glass micropipette was lowered at a $9^{\circ}$ angle from the vertical to avoid passage through HVC en route to RA. Fluorogold ( $2 \%$ in $0.9 \% \mathrm{NaCl}$; Fluorochrome Inc.) or fluorescent beads were pressure injected into RA. Injections (10-20 nl each) were made into RA at four different sets of coordinates to maximize retrograde fills.

Histology. Three days after tracer injections, each canary received an overdose of Chloropent and was then perfused through the heart with $0.9 \%$ saline followed by $4 \%$ paraformaldehyde in $0.1 \mathrm{M}$ phosphate buffer. Brains were removed and postfixed for $1-7 \mathrm{~d}$ in the same fixative. Hemispheres with fluorogold injections were dehydrated with graded 

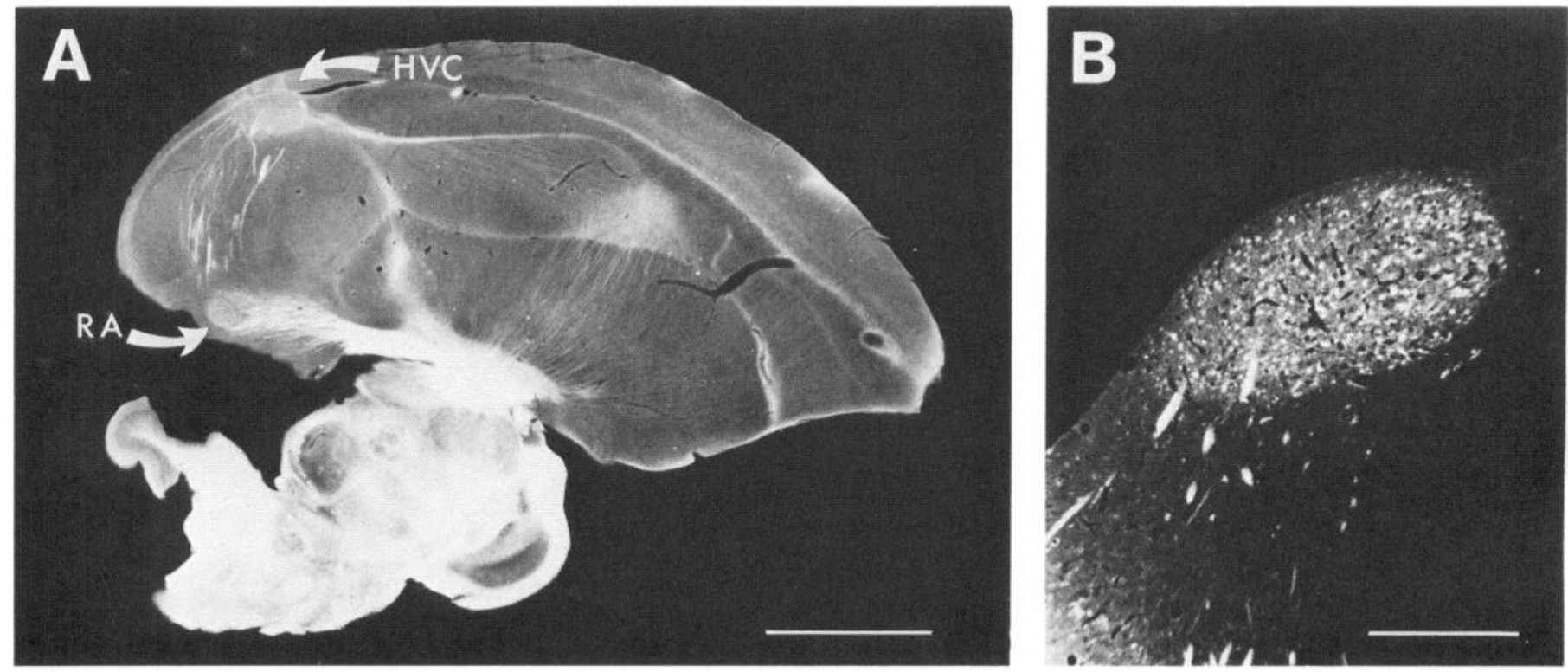

Figure 1. A, Dark-field photomicrograph of an unstained parasagittal section of adult canary brain. Major fiber tracts and areas rich in neuropil appear white. HVC and RA form part of the efferent pathway for the control of learned song. Over half of HVC neurons project to RA, and the axons of these cells join fascicles that can be seen arching from HVC toward RA. New RA-projecting HVC neurons continue to be recruited in adulthood. Dorsal is $u p$, and rostral is to the right. Scale bar, $2 \mathrm{~mm}$. B, Fluorescence photomicrograph of HVC retrogradely labeled by fluorogold injections into RA. Scale bar, $500 \mu \mathrm{m}$.

concentrations of ethyl alcohol and embedded in polyethylene glycol (PEG; Clayton and Alvarez-Buylla, 1989). Sagittal 6- $\mu \mathrm{m}$ sections encompassing HVC and RA were cut on a rotary microtome and mounted on chrom-alum-subbed slides. Sections were then delipidized and rehydrated, dipped in emulsion (Kodak, NBT-2), and stored in the dark at $4^{\circ} \mathrm{C}$ for $30 \mathrm{~d}$. Slides were then developed for $3 \mathrm{~min}$ at $17^{\circ} \mathrm{C}$ in D19 developer (Kodak), washed in distilled water, and counterstained through the emulsion with fluorescent cresyl violet (Alvarez-Buylla et al., 1990b). Following dehydration in alcohols and clearing in xylene, sections were coverslipped with Krystalon (Harleco/EM Diagnostic Systems Inc.). This protocol permits sequential visualization of autoradiographic silver grains under bright-field illumination and of fluorogold and cresyl violet using fluorescent light (Nikon filter sets UV-1A and G-1A for fluorogold and fluorescent cresyl violet counterstain, respectively). Data were collected with a computer-yoked microscope that has been described in detail elsewhere (Alvarez-Buylla and Vicario, 1988).

Hemispheres with bead injections were processed somewhat differently due to the vulnerability of beads to alcohols (Katz et al., 1984). Following fixation as described for fluorogold, tissue was cryoprotected by immersion in $30 \%$ sucrose in $0.1 \mathrm{M}$ phosphate buffer for $24 \mathrm{hr}$ and then embedded in Tissue Tek (Miles Inc.). Tissue blocks were frozen in a bath of hexane immersed in liquid nitrogen and cut in the sagittal plane on a cryostat. Six-micron sections were thaw mounted onto chromalum-subbed slides, air dried, rinsed briefly in $0.1 \mathrm{~m}$ phosphate buffer, dried again, passed briefly through xylene, dried again, and then rehydrated and dipped in emulsion according to the protocol described above. Following autoradiographic development, sections were counterstained with Hoechst 33258 (Aldrich).

HVC analyses. Twelve equally spaced sections through HVC (approximately $0.02 \mathrm{~mm}^{3}$ or $8 \%$ of total HVC volume) were completely scanned for autoradiographically labeled neurons. A $20 \times$ background labeling criterion was employed, and only cells with a clear nucleus and one or two darkly staining nucleoli were classified as ${ }^{3} \mathrm{H}$-labeled neurons. ${ }^{3} \mathrm{H}$-labeled neurons were also scored for the presence or absence of fluorogold in their cytoplasm. In four of these sections, all fluorogoldlabeled cells and all HVC neurons.were also counted. Cell nuclear diameters were measured in samples of at least 50 neurons in each of four staining categories per animal: (1) ${ }^{3} \mathrm{H}$-positive and fluorogold positive, (2) ${ }^{3} \mathrm{H}$-positive and fluorogold negative, (3) ${ }^{3} \mathrm{H}$-negative and fluorogold positive, and (4) ${ }^{3} \mathrm{H}$-negative and fluorogold negative.

Counts of neurons that were not autoradiographically labeled were corrected for cell splitting (Weibel, 1979; Clark et al., 1990) and yielded estimates of number of neurons per unit of HVC volume. The very stringent criterion for autoradiographic labeling we used, based on mean nuclear diameter, tends to ignore small pieces of ${ }^{3} \mathrm{H}$-labeled nuclei, which rarely if ever meet criterion level (Clark et al., 1990). This minimizes potential double-counting errors and, within the range of nuclear diameters found in our material, made it unnecessary to correct for the splitting of ${ }^{3} \mathrm{H}$-labeled neuronal nuclei.

Total volume of HVC was estimated by tracing the perimeter of HVC, as defined by fluorogold backfills (see Fig. $1 B$ ), in sections at $120-\mu \mathrm{m}$ intervals (12-14 sections per HVC); areas derived in this manner were then multiplied by the sampling interval. Volume estimates were then used to calculate the total number of HVC neurons, of fluorogoldbackfilled HVC neurons, of ${ }^{3} \mathrm{H}$-labeled HVC neurons, and of ${ }^{3} \mathrm{H}$-labeled fluorogold-backfilled HVC neurons. In some animals, fluorogold injections missed RA on one side of the brain. When this occurred, values from the remaining hemisphere were used. In cases where fluorogold injections were on target in both hemispheres, values for left and right HVC were averaged together. We found no evidence of systematic leftright differences in any of the measurements obtained.

Data collection for birds injected with fluorescent beads was similar to that for fluorogold-injected birds. Twelve sections through HVC were completely scanned for ${ }^{3} \mathrm{H}$-labeled neurons. The number of such cells that were also retrogradely labeled with beads was divided by the volume sampled to generate double-labeled cell densities. ${ }^{3} \mathrm{H}$-bead cell density data were used for comparing the efficacy of beads and fluorogold.

Ventricular zone analyses. Preliminary observations revealed that some ventricular zone (VZ) cells immediately above $\mathrm{HVC}$ retained ${ }^{3} \mathrm{H}$-label after long survivals in many of the birds used. As this region of VZ represents the shortest possible route for migration of new neurons into HVC, it may be a site for the formation of HVC neurons. More important for the present study was the concern that divisions of ${ }^{3} \mathrm{H}$-labeled VZ cells may have occurred and contributed new HVC neurons 30 or more days after the last ${ }^{3} \mathrm{H}$-thymidine injection. If true, then late addition of ${ }^{3} \mathrm{H}$-thymidine-labeled HVC neurons would contaminate survivorship estimates. To determine whether or not the population of ${ }^{3} \mathrm{H}$ labeled VZ cells was stable over time, the VZ-one or two cells deep and therefore a linear dimension-overlying HVC was scanned for labeled cells in five equally spaced sections in each bird. A $20 \times$ labeling criterion was employed, and the number of labeled VZ cells per millimeter of ventricular zone was calculated. Silver grains over labeled VZ cell nuclei were counted, and the average number of grains per cell was derived.

Statistics. Data were analyzed with one- or two-way analysis of variance (ANOVA). Data expressed as proportions were subjected to arcsine 
A

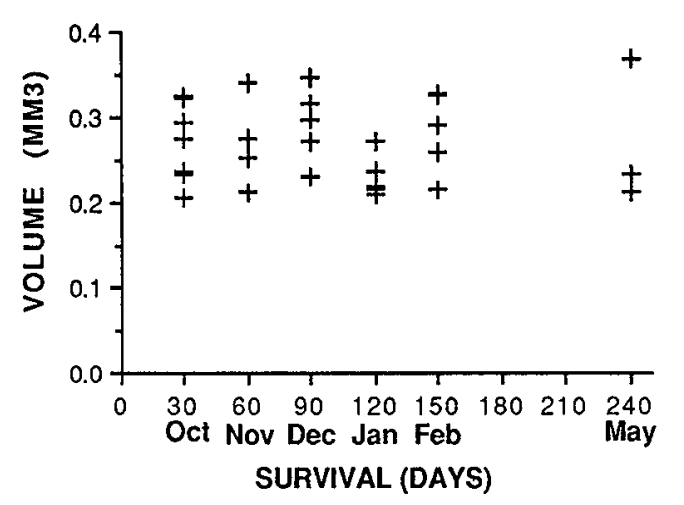

C

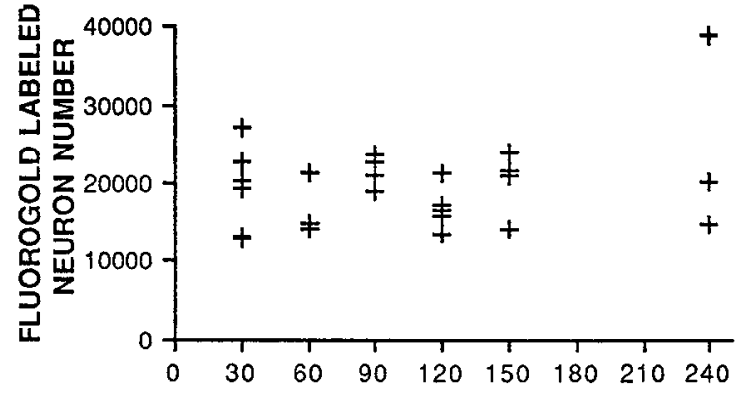

B

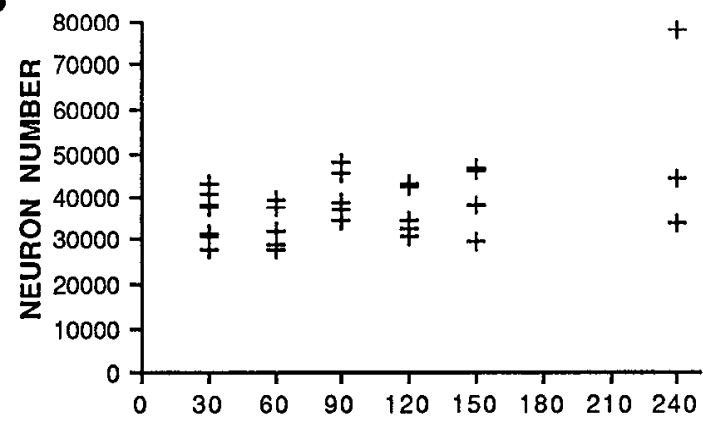

D

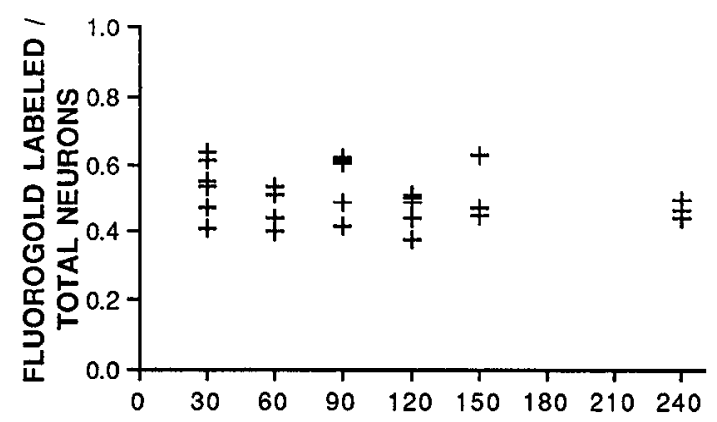

Figure 2. Estimates of HVC volume $(A)$, total HVC neuron number $(B)$, total RA-projecting HVC neuron number ( $C$ ), and the proportion of HVC neurons that are RA-projecting at various survival times after ${ }^{3} \mathrm{H}$-thymidine treatment $(D)$. Survival times are plotted in days and months sampled. In this and all graphs that follow, the months of March and April (180 and $210 \mathrm{~d}$, respectively) were not sampled. Each data point represents data for one animal.

transformation prior to statistical analysis (Sokal and Rohlf, 1981). Sample sizes after excluding animals with off-target fluorogold injections were $n=7$ for $30 \mathrm{~d}, n=4$ for $60 \mathrm{~d}, n=5$ for $120 \mathrm{~d}, n=4$ for $150 \mathrm{~d}$, and $n=3$ for $240 \mathrm{~d}$.

\section{Results}

Monthly estimates of HVC volume, total neuron number, RAprojecting neuron number, and proportion of HVC neurons that were RA-projecting are summarized in Figure $2 A-D$. The volume of $\mathrm{HVC}$ did not differ significantly between birds killed in October, November, December, January, February, and May $[F(5,22)=0.99 ; p=0.44]$. Similarly, the total number of HVC neurons and number of RA-projecting $\mathrm{HVC}$ neurons showed little variability over the months sampled $[F(5,22)=1.79, p=$ 0.16 for total HVC neurons; $F(5,22)=1.37, p=0.27$ for RAprojecting neurons]. No significant differences were found in the proportion of HVC neurons that projected to RA during the months examined $[F(5,22)=1.14 ; p=0.37]$. In addition, estimates of the total number of ${ }^{3} \mathrm{H}$-labeled $\mathrm{HVC}$ neurons were very comparable for each of the survival times sampled [Fig. $3 A ; F(5,22)=0.39 ; p=0.85)$.

Examples of ${ }^{3} \mathrm{H}$-labeled neurons that were backfilled with fluorogold or fluorescent beads are shown in Figure 4. The number of ${ }^{3} \mathrm{H}$-labeled HVC neurons backfilled with fluorogold at 30 $\mathrm{d}$ was similar to that backfilled with fluorescent beads [Fig. 5; $F(1,4)=0.19 ; p=0.69$ ]. This confirmed that fluorogold marked only backfilled cells and that it did not leak from such cells to others in close contact. Therefore, our ${ }^{3} \mathrm{H}$-labeled fluorogoldbackfilled HVC cells were RA-projecting neurons (see also Alvarez-Buylla et al., 1990a).

The percentage of ${ }^{3} \mathrm{H}$-labeled $\mathrm{HVC}$ neurons that projected to RA varied considerably during October, November, and December, in animals that survived 30,60 , and $90 \mathrm{~d}$, respectively (Fig. $3 B$ ). There was less variability in this distribution during January, February, and May, 120, 150, and $240 \mathrm{~d}$ after ${ }^{3} \mathrm{H}-$ thymidine injection, respectively. At longer survival times, fewer birds showed relatively low percentages of ${ }^{3} \mathrm{H}$-labeled cells backfilled with fluorogold. As a result, the mean percentage of ${ }^{3} \mathrm{H}$-labclcd HVC neurons backfilled with fluorogold increased by $50 \%$ between October and May. This increase was gradual (Fig. 3B). A comparison between the Octoher plus November samples (pooled) versus the February plus May samples (pooled) shows that this change was statistically significant $[F(1,16)=$ $10.36 ; p=0.005]$. However, there were at all survival times some birds that had somewhere between $60 \%$ and $75 \%$ of their ${ }^{3} \mathrm{H}$-labeled HVC cells backfilled with fluorogold (Fig. 3B).

Nuclear diameters for fluorogold-labeled neurons, ${ }^{3} \mathrm{H}$-labeled neurons that were not backfilled with fluorogold, and doublelabeled neurons in HVC at 30 and 240 d survival are summarized in Figure 6. ANOVA revealed a significant interaction between the size of nuclei associated with a particular type of labeling and survival $[F(2,24)=6.56 ; p=0.01]$. The nuclear diameters of $\mathrm{HVC}$ cells backfilled with fluorogold did not change between 30 and $240 \mathrm{~d}$ survival $[F(1,9)=0.60 ; p=0.46$ ). How- 
ever, the nuclear diameters of HVC neurons that were double labeled with ${ }^{3} \mathrm{H}$-thymidine and fluorogold at $30 \mathrm{~d}$ were significantly larger than those of the general population of fluorogoldbackfilled neurons $[F(1,12)=27.20 ; p=0.0002]$. In contrast, at $240 \mathrm{~d}$ survival, the nuclear diameters of double-labeled $\mathrm{HVC}$ neurons were not significantly different from those of $\mathrm{HVC}$ neurons labeled with fluorogold alone $[F(1,4)=0.56 ; p=0.49]$. The same shift from larger to smaller diameters between 30 and 240-d survival times was also reflected in the population of ${ }^{3} \mathrm{H}$-labeled HVC neurons that were not backfilled with fluorogold $[F(1,8)=19.69 ; p=0.002]$.

The number of ${ }^{3} \mathrm{H}$-labeled $\mathrm{VZ}$ cells overlying $\mathrm{HVC}$ and the average number of silver grains per labeled VZ cell (Fig. $7 A, B$, respectively) remained very similar between 30 and $240 \mathrm{~d}$ after administration of ${ }^{3} \mathrm{H}$-thymidinc $[F(5,22)=0.57, p=0.72$ for ${ }^{3} \mathrm{H}$-labeled VZ cells; $F(5,22)=0.44, p=0.81$ for average silver grains per labeled VZ cell]. When pooling the data from all survivals together, there was a significant positive correlation between the number of labeled VZ cells overlying $\mathrm{HVC}$ and the percentage of HVC neurons that were ${ }^{3} \mathrm{H}$-labeled (Fig. $7 C ; r=$ $0.59 ; p=0.0009$ ).

\section{Discussion}

In the present study, we followed the fate of a cohort of neurons born in September in adult male canaries. We show that most of these new neurons survive at least until the following spring ( 8 months later). In addition, we demonstrated that many adultformed HVC neurons project to nucleus RA, and that the proportion of such cells increases with long survivals.

\section{Survival of HVC neurons born in adulthood}

The number of new HVC neurons stayed fairly constant between 60 and $240 \mathrm{~d}$ after the injections of ${ }^{3} \mathrm{H}$-thymidine. This suggests that the great majority (all?) of new HVC neurons born in midSeptember and that had acquired an adult phenotype by $60 \mathrm{~d}$ survived at least 8 months. We cannot speak with equal confidence about what happened between 30 and $60 \mathrm{~d}$, because at day 30 there may have been ${ }^{3} \mathrm{H}$-labeled neurons still in the process of migration, and which therefore were not recognized and counted. We cannot rule out the possibility that some of the new neurons that had differentiated by $30 \mathrm{~d}$ were replaced soon thereafter by later arrivals.

It is unlikely that ${ }^{3} \mathrm{H}$-labeled VZ cells underwent further divisions, contributing new neurons at intervals 30 or more days after ${ }^{3} \mathrm{H}$-thymidine administration. The number of ${ }^{3} \mathrm{H}-\mathrm{VZ}$ cells at the level of the anterior commissure (VZ proliferation is particularly high at this level) decreases rapidly after ${ }^{3} \mathrm{H}$-thymidine injections (Alvarez-Buylla and Nottebohm, 1988). Although in the present experiment the VZ above $\mathrm{HVC}$ revealed significant numbers of ${ }^{3} \mathrm{H}$-labeled cells even at the longer survivals, these cells appear not to divide after $30 \mathrm{~d}$. The number of ${ }^{3} \mathrm{H}-\mathrm{VZ}$ cells overlying $\mathrm{HVC}$ was similar at 30 and $240 \mathrm{~d}$ after ${ }^{3} \mathrm{H}$-thymidine injections. This finding, taken together with the stable number of exposed silver grains overlying VZ cell nuclei, suggests that these cells did not divide again between October and May.

Interestingly, there was a partial correlation between the number of ${ }^{3} \mathrm{H}$-labeled VZ cells over HVC and the proportion of $\mathrm{HVC}$ neurons labeled with ${ }^{3} \mathrm{H}$-thymidine. Unfortunately, we do not know whether the ${ }^{3} \mathrm{H}$-labeled VZ cells that persist up to 240 $\mathrm{d}$ are part of the neurogenesis cycle (e.g., labeled stem cells) or represent a cell type not involved in neurogenesis that is replaced
A

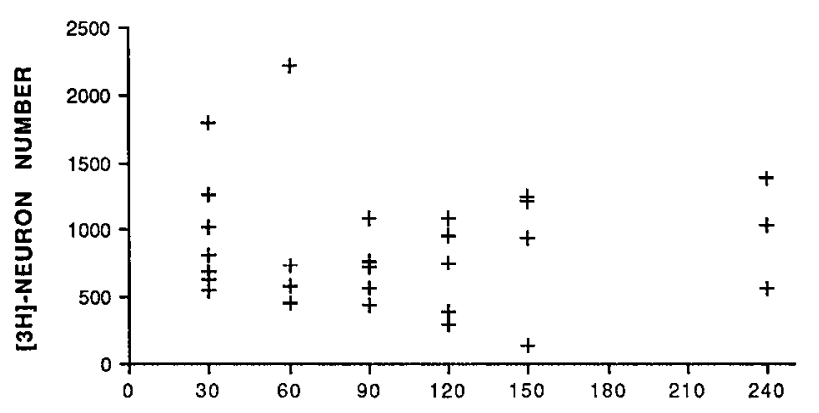

B

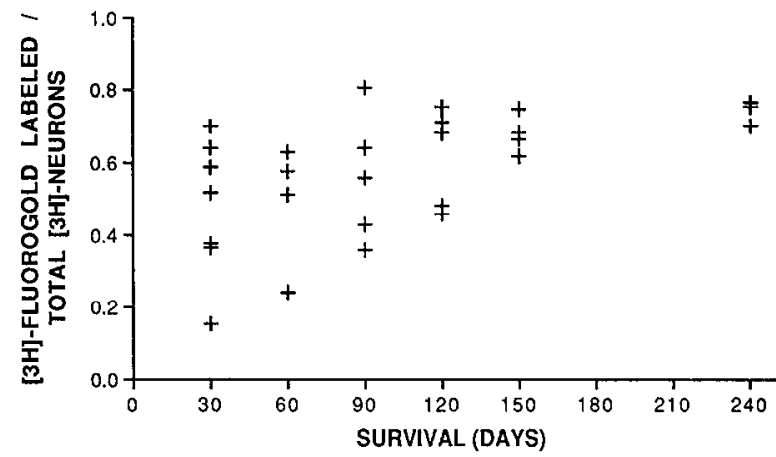

Figure 3. $A$, Estimates of tolal ${ }^{3} \mathrm{H}$-labeled $\mathrm{HVC}$ neuron number at various survival times after ${ }^{3} \mathrm{H}$-thymidine treatment. $B$, The proportion of total ${ }^{3} \mathrm{H}$-labeled HVC neurons that were also retrogradely labeled with fluorogold injections into RA.

at intervals longer than 8 months. If the former is the case, then perhaps some HVC neurons are generated only once every 8 months, or yearly, and the VZ cells that give rise to them also divide only with that interval.

There is in January-February a crash in the blood levels of circulating testosterone in adult male canaries. At that time song becomes unstable, though not as plastic as in late summer, and some new syllable types are created (Nottebohm et al., 1987). Our data suggest that neurons born in mid-September survive this period of behavioral and hormonal change.

\section{Phenotype of adult-formed HVC neurons}

Our observations indicate that as much as $80 \%$ of new HVC neurons born in mid-September become RA-projecting neurons. We cannot be sure whether the remaining $20 \%$ are true interneurons or merely RA-projecting cells that failed to transport fluorogold. It is unlikely that these new neurons project to area X, the other target of HVC neurons (Nottebohm et al., 1976, 1982; Bottjer et al., 1989) because most (all?) area X-projecting HVC neurons are formed before hatching (Alvarez-Buylla et al., 1988).

Results from an earlier study suggested that few, if any, RAprojecting HVC neurons were born in adult male canaries, and that the majority of neurons recruited into the adult HVC were interneurons (Paton et al., 1985). In this earlier experiment, HRP was used as a retrograde marker. We have not compared the HRP method with the fluorescent method used in this study 

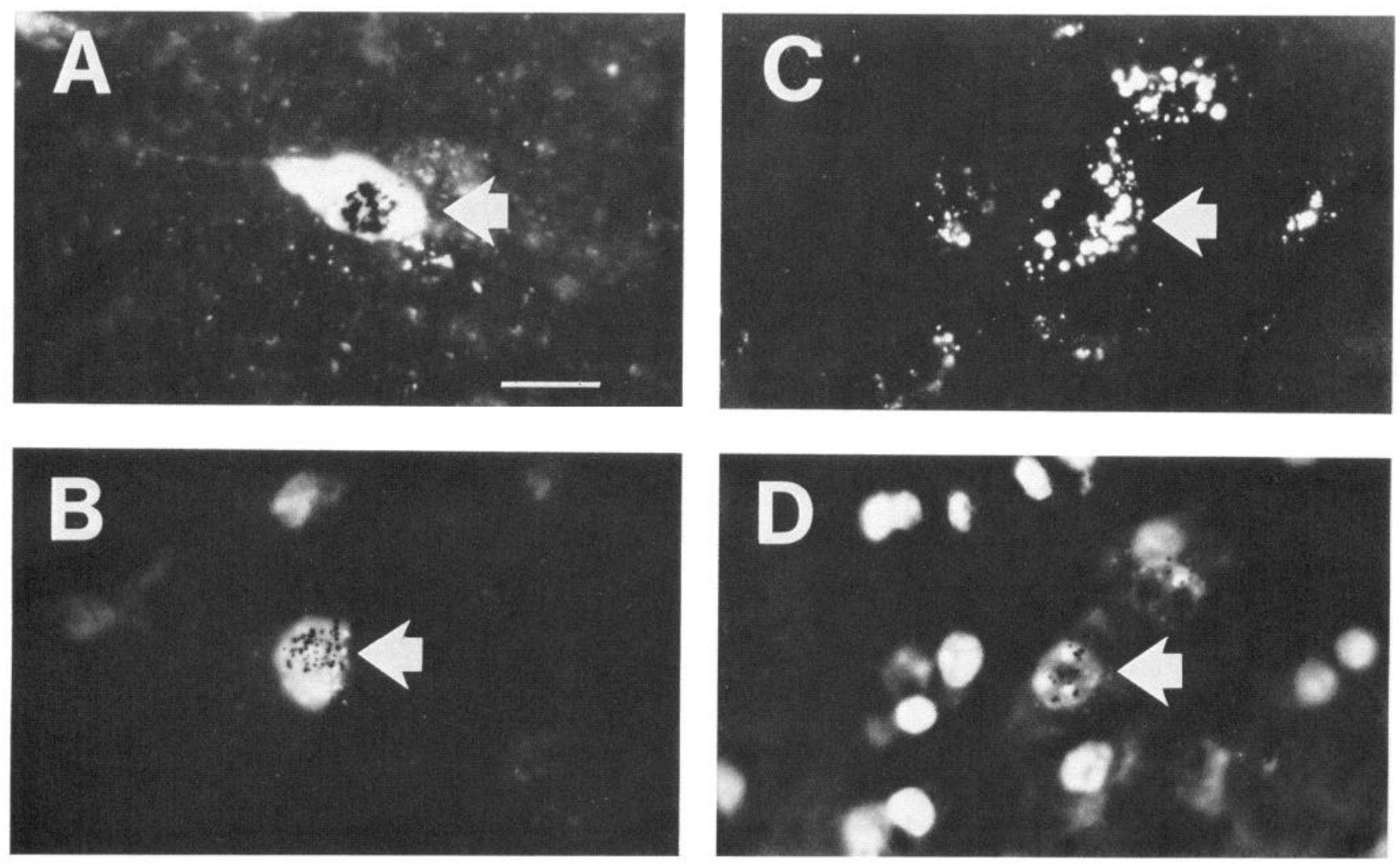

Figure 4. Fluorescent photomicrographs of $\mathrm{HVC}$ projection neurons born in adulthood (arrows). Adult birds pretreated with ${ }^{3} \mathrm{H}$-thymidine were injected in RA with the retrograde tracers fluorogold or fluorescent latex microspheres. $A$ and $B$, Examples of cells with ${ }^{3} \mathrm{H}$-labeled nuclei (documenting their birth in adult birds) and cytoplasmic fluorogold label (indicating that these cells projected from HVC to RA). $C$ and $D$, An example of an HVC neuron retrogradely labeled with fluorescent latex microspheres and ${ }^{3} \mathrm{H}$-thymidine. $C$, Under rhodamine fluorescence, microspheres can be seen in a cytoplasmic ring surrounding a nonfluorescing nucleus. $D$, The same tissue field as in $C$, now viewed with wide-band UV light to reveal Hoechst counterstained cell nucleus with overlying ${ }^{3} \mathrm{H}$-label. Scale bar, $10 \mu \mathrm{m}$.

for backfilling ${ }^{3} \mathrm{H}$-labeled cells. However, HRP labels on average $11 \%$ of HVC neurons (Paton et al., 1985). In contrast, fluorogold and fluorescent beads backfilled $40-60 \%$ of HVC neurons in the present study, suggesting that HRP backfills underestimate the

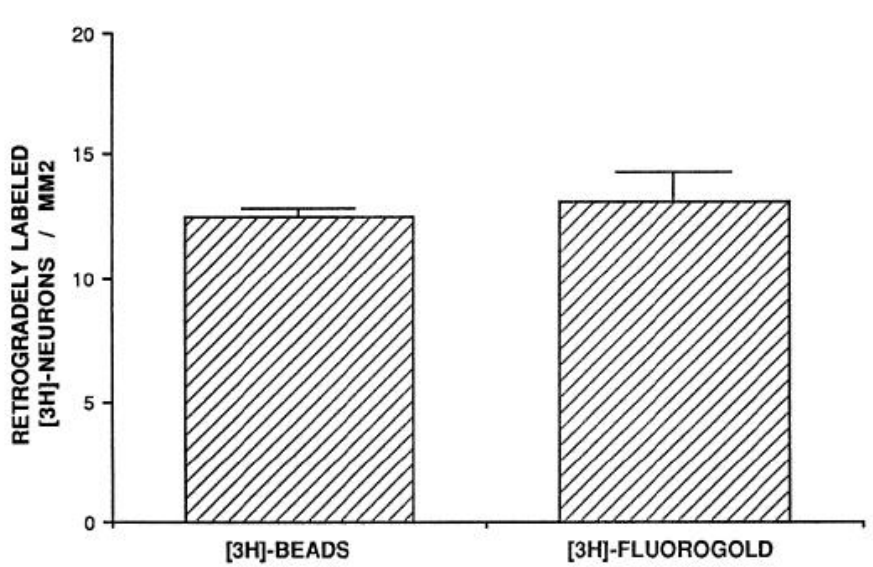

Figure 5. Demonstration of the birth of projection neurons in adult canaries using two different retrograde tracers in combination with ${ }^{3} \mathrm{H}$ thymidine: mean ( \pm SEM) density of ${ }^{3} \mathrm{H}$-labeled HVC neurons retrogradely filled from RA with either fluorogold or fluorescent latex microspheres (beads) $30 \mathrm{~d}$ after ${ }^{3} \mathrm{H}$-thymidine treatment. true number of HVC cells that project to RA (see also AlvarezBuylla et al., 1990a). Other authors have also shown that fluorescent tracers are more efficient than HRP as retrograde markers (Sawchenko and Swanson, 1981).

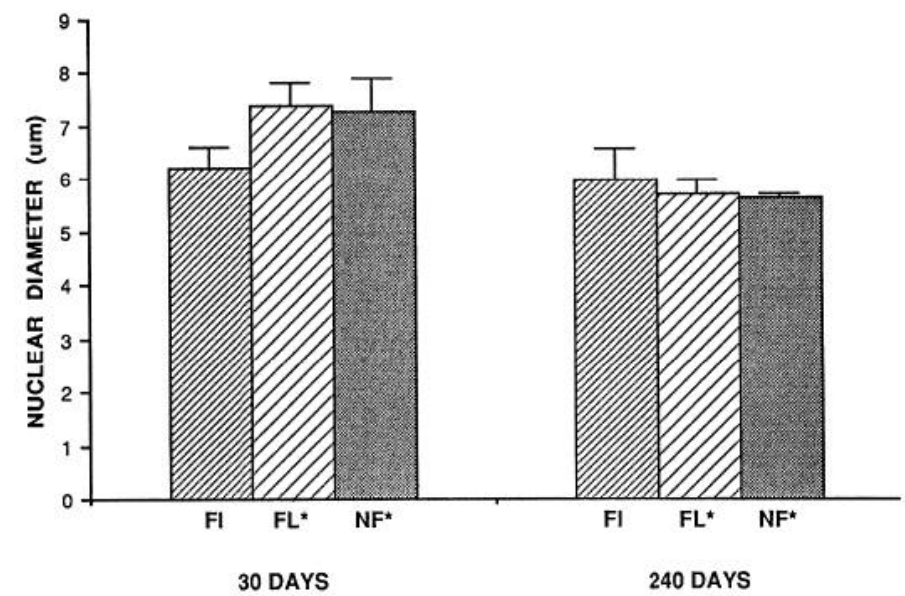

Figure 6. Neuronal nuclear diameter measurements for HVC neurons that were fluorogold positive and ${ }^{3} \mathrm{H}$-negative $(F l)$, fluorogold positive and ${ }^{3} \mathrm{H}$-positive $\left(F L^{*}\right)$, and fluorogold negative and ${ }^{3} \mathrm{H}$-positive $\left(N F^{*}\right)$ at 30 and $240 \mathrm{~d}$ survival following ${ }^{3} \mathrm{H}$-thymidine treatment. Average nuclear diameters were obtained from each animal, and these values were averaged to derive mean $( \pm$ SEM) nuclear diameters for each of the survival times. 
Acquisition of the $R A$-projecting phenotype

The number of new, ${ }^{3} \mathrm{H}$-labeled HVC neurons did not increase after $30 \mathrm{~d}$, but the fraction of these neurons that projected to RA did. The time course of change in this ratio puzzles us. If the new HVC neurons are born in the VZ overlying HVC, then their migration into $\mathrm{HVC}$ probably ends 2 weeks after neuronal birth. Neurons traveling over much longer distances, also in adult canary telencephalon, reach their destinations as early as $15 \mathrm{~d}$ (Alvarez-Buylla and Nottebohm, 1988). Thus, axons of new HVC neurons in the present study probably had at least $15 \mathrm{~d}$ to grow from HVC to RA before the earliest fluorogold injections. This estimate of time allotted for axon growth may be conservative, because axon growth could start even before the cell body has reached its destination.

Several factors could account for the apparent increase in new projection neurons over time. Newly formed axons may not be as effective as older axons at transporting fluorogold from the periphery to the soma. If so, we would underestimate the proportion of ${ }^{3} \mathrm{H}$-labeled neurons that project to RA at earlier survival times. It is also possible that not all new HVC cells destined to project to RA grow their axons at a comparable rate, and this also could lead to an underestimate of new RA-projecting neurons. It is even possible that some of the new neurons first become interneurons and only later grow a long axon to RA.

In the present study, short survivals were associated with greater variability than long survivals in the percentage of ${ }^{3} \mathrm{H}$ labeled HVC neurons that were backfilled with fluorogold, a fact that contributed to the observed increase in new projection neurons with longer survivals. This interindividual variability might be explained by individual differences in circulating hormones. For example, the levels of testosterone in aduit canary males become quite low during mid-summer and start rising again in the fall. The timing of these changes among individuals kept under similar conditions can vary by as much as a month or more (Nottebohm et al., 1987). Individual differences in levels of circulating hormones could affect rate of axonal growth and/or the retrograde transport of fluorogold.

The nuclear diameters of ${ }^{3} \mathrm{H}$-labeled $\mathrm{HVC}$ neurons were larger at $30 \mathrm{~d}$ than at $240 \mathrm{~d}$ survival time. The significance of this change is unclear. One possibility is that at earlier survival times neurites were still growing and nuclei were more active in processes related to protein synthesis. Nuclear size could also correlate with other aspects of cell anatomy. For example, neurons born in adult canary brain may show an early exuberance of axonal and dendritic arborization, which is subsequently pared, as is true for neurons born during embryogenesis (Cowan et al., 1984). It is also possible that cell nuclear shrinkage represents part of the aging process for mature neurons whose ultimate fate is death and replacement.

\section{Neuronal replacement}

One of the properties of HVC that seemed most tantalizing when first described was its apparent seasonal change in volumelarge in the spring, small in late summer (Nottebohm, 1981). That property was rcadily seen when using a Nissl stain, such as cresyl violet, to demarcate the boundaries of HVC. However, staining intensity may vary as a function of protein synthesis (Gahr, 1990), metabolic state, and/or other aspects of cell function. These changes in metabolism can affect the perceived position of an anatomical boundary. A different and more reliable method of HVC staining, using backfills from area $\mathrm{X}$, showed
A

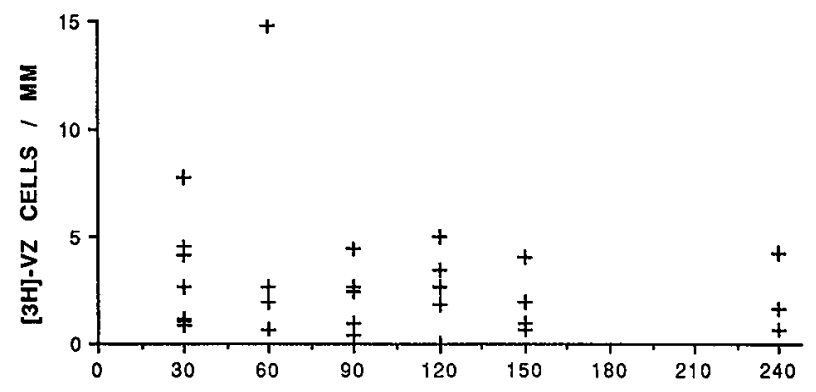

B
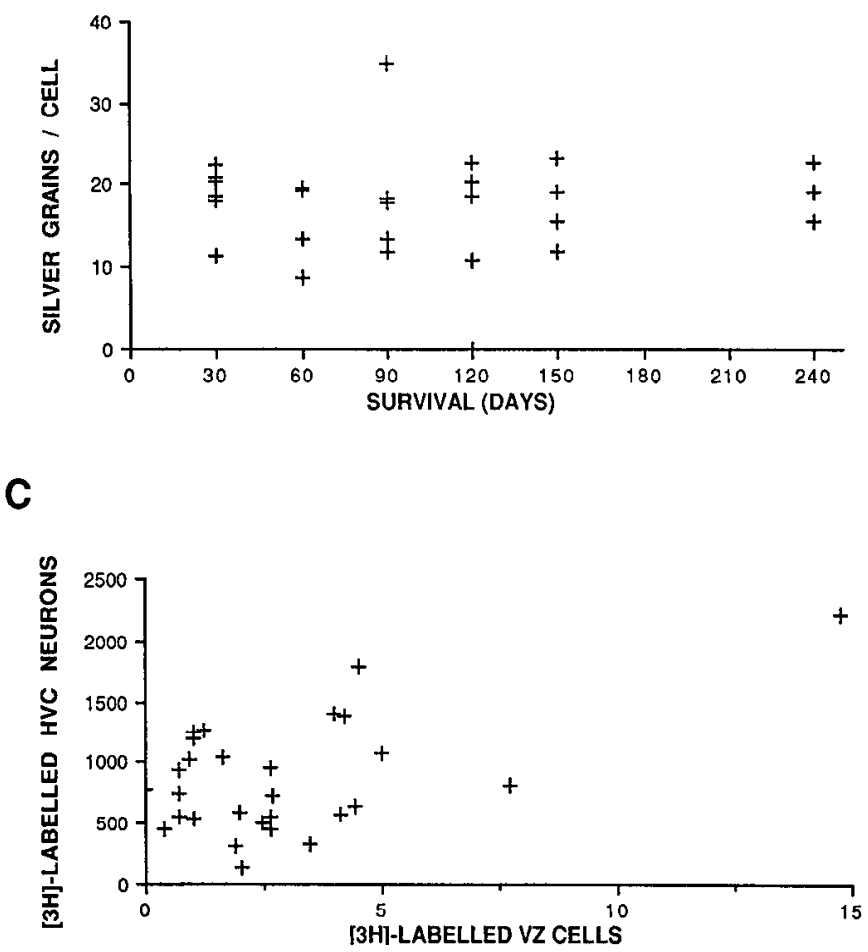

Figure 7. Analyses of ${ }^{3} \mathrm{H}$-labeling in the $\mathrm{VZ}$ above $\mathrm{HVC}$ at various survival times following ${ }^{3} \mathrm{H}$-thymidine injections. $A$, Density of ${ }^{3} \mathrm{H}-$ labeled VZcells per millimeter. $B$, Mean number of exposed silver grains over ${ }^{3} \mathrm{H}$-labeled VZ cells. $C$, ${ }^{3} \mathrm{H}$-labeled VZ cells per millimeter plotted against the number of ${ }^{3} \mathrm{H}$-labeled neurons in $\mathrm{HVC}$ of the same animals.

that HVC boundaries do not change seasonally (Gahr, 1990). The present study, in which cells backfilled from RA were used to determine the perimeter of $\mathrm{HVC}$, also failed to uncover seasonal changes in HVC volume, and our HVC neuronal counts remained stable between October and May. Thus, the seasonal HVC volume changes claimed in the earlier report (Nottebohm, 1981) may, in fact, have reflected seasonal variation in protein synthesis or metabolic activity. Nonetheless, new HVC neurons are produced in adult canaries during all months of the year (Paton et al., 1985; Alvarez-Buylla et al., 1990a; F. Nottebohm, unpublished observations; present results), and so the new neurons must be part of a constant replacement process. However, we do not yet know how this replacement occurs.

\section{Summary}

Our results using fluorogold and fluorescent beads demonstrate that a majority of the HVC neurons born during the month of 
September in adult male canaries become RA-projecting neurons and survive for at least 8 months. Canaries modify their song in the fall, and most of the new song repertuire persists until the end of the following breeding season (Nottebohm and Nottebohm, 1978; Nottebohm et al., 1987). The Septemberborn RA-projecting neurons may play an important role in the yearly acquisition and retention of a new song repertoire.

\section{References}

Alvarez-Buylla A, Nottebohm F (1988) Migration of young neurons in adult avian brain. Nature 335:353-354.

Alvarez-Buylla A, Vicario DS (1988) Simple microcomputer system for mapping tissue sections with the light microscope. J Neurosci Methods 25:165-173.

Alvarez-Buylla A, Theelen M, Nottebohm F (1988) Birth of projection neurons in the higher vocal center of the canary forebrain before, during, and after song learning. Proc Natl Acad Sci USA 85:87228726.

Alvarez-Buylla A, Kirn JR, Nottebohm F (1990a) Birth of projection neurons in adult avian brain may be related to perceptual or motor learning. Science 249:1444-1446.

Alvarez-Buylla A, Ling C-Y, Kirn JR (1990b) Cresyl violet: a red fluorescent Nissl stain. J Neurosci Methods 33:129-133.

Bottjer SW, Halsema KA, Brown SA, Miesner EA (1989) Axonal connections of a forebrain nucleus involved with vocal learning in zebra finches. J Comp Neurol 279:312-326.

Burd GD, Nottebohm F (1985) Ultrastructural characterization of synaptic terminals formed on newly generated neurons in a song control nucleus of the adult canary forebrain. J Comp Neurol 240: 143-152.

Clark SJ, Cynx J, Alvarez-Buylla A, O'Loughlin B, Nottebohm F (1990) On variables that affect estimates of the true sizes and densities of radioactively labeled cell nuclei. J Comp Neurol 301:114-122.

Clayton DF, Alvarez-Buylla A (1989) In situ hybridization using PEGembedded tissue and riboprobes: increased cellular detail coupled with high sensitivity. J Histochem Cytochem 37:389-393.

Cowan WM, Fawcett JW, O'Leary DDM, Stanfield BB (1984) Regressive events in neurogenesis. Science 225:1258-1265.

Gahr M (1990) Delineation of a brain nucleus: comparisons of cytochemical, hodological, and cytoarchitectural views of the song control nucleus HVC of the adult canary. J Comp Neurol 294:30-36.

Goldman SA, Nottebohm F (1983) Neuronal production, migration, and differentiation in a vocal control nucleus of the adult female canary brain. Proc Natl Acad Sci USA 80:2390-2394.
Katz LC, Burkhalter A, Dreyer WJ (1984) Fluorescent latex microspheres as a retrograde neuronal marker for in vivo and in vitro studies of visual cortex. Nature 310:498-500.

Marler P, Waser MS (1977) Role of auditory feedback in canary song development. J Comp Physiol Psychol 91:8-16.

McCasland JS, Konishi M (1981) Interaction between auditory and motor activities in an avian song control nucleus. Proc Natl Acad Sci USA 78:7815-7819.

Nottebohm F (1981) A brain for all seasons: cyclical anatomical changes in song control nuclei of the canary brain. Science 214:1368-1370.

Nottebohm F (1985) Neuronal replacement in adulthood. In: Hope for a new neurology, Vol 457 (Nottebohm F, ed), pp 143-161. New York: New York Academy of Sciences.

Nottebohm F (1989) From bird song to neurogenesis. Sci Am 260: $74-79$.

Nottebohm F, Nottebohm ME (1978) Relationship between song repertoire and age in the canary, Serinus canarius. Z. Tierpsychol 46: 298-305.

Nottebohm F, Stokes TM, Leonard CM (1976) Central control of song in the canary, Serinus canaria. J Comp Neurol 165:457-486.

Nottebohm F, Kelley DB, Paton JA (1982) Connections of vocal control nuclei in the canary telencephalon. J Comp Neurol 207:344357.

Nottebohm F, Nottebohm ME, Crane LA, Wingfield JC (1987) Seasonal changes in gonadal hormone levels of adult male canaries and their relation to song. Behav Neural Biol 47:197-211.

Paton JA, Nottebohm F (1984) Neurons generated in the adult brain are recruited into functional circuits. Science 225:1046-1048.

Paton JA, O'Loughlin BE, Nottebohm F (1985) Cells born in adult canary forebrain are local interneurons. J Neurosci 5:3088-3093.

Sawchenko PE, Swanson LW (1981) A method for tracing biochemically defined pathways in the central nervous system using combined fluorescence retrograde transport and immunohistochemical techniques. Brain Res 210:31-51.

Schmued LC, Fallon JH (1986) Fluoro-gold: a new fluorescent retrograde axonal tracer with numerous unique properties. Brain Res 377:147-154

Simpson HB, Vicario DS (1990) Brain pathways for learned and unlearned vocalizations differ in zebra finches. J Neurosci 10:15411556.

Sokal RR, Rohlf FJ (1981) Biometry. New York: Freeman.

Stokes TM, Leonard CM, Nottebohm F (1974) The telencephalon, diencephalon, and mesencephalon of the canary, Serinus canaria, in stereotaxic coordinates. J Comp Neurol 156:337-374.

Weibel ER (1979) Stereological methods, Vol 1, Practical methods for biological morphometry. New York: Academy. 